This item was submitted to Loughborough's Research Repository by the author.

Items in Figshare are protected by copyright, with all rights reserved, unless otherwise indicated.

\title{
Employer perspectives concerning the self-management support needs of workers with long-term health conditions
}

PLEASE CITE THE PUBLISHED VERSION

https://doi.org/10.1108/IJWHM-02-2021-0030

PUBLISHER

Emerald

VERSION

AM (Accepted Manuscript)

\section{PUBLISHER STATEMENT}

This paper was accepted for publication in the journal International Journal of Workplace Health Management and the definitive published version is available at https://doi.org/10.1108/IJWHM-02-2021-0030

LICENCE

CC BY-NC 4.0

\section{REPOSITORY RECORD}

Hemming, Sally, Hilary McDermott, Fehmidah Munir, and Kim Burton. 2021. "Employer Perspectives Concerning the Self-management Support Needs of Workers with Long-term Health Conditions". Loughborough University. https://hdl.handle.net/2134/14723754.v1. 


\section{International Journal of Workplace Health Manag}

\section{Employer Perspectives Concerning the Self-Management Support Needs of Workers with Long-Term Health Conditions}

\begin{tabular}{|r|l|}
\hline Journal: & International Journal of Workplace Health Management \\
\hline Manuscript ID & IJWHM-02-2021-0030.R1 \\
\hline Manuscript Type: & Research Paper \\
\hline Keywords: & $\begin{array}{l}\text { Employers, Self management, Chronic health, Self-efficacy, Long-term } \\
\text { health conditions, Psychosocial health }\end{array}$ \\
\hline
\end{tabular}

\section{SCHOLARONE \\ Manuscripts}




\begin{abstract}
Design: The exploration of employers' views involved recruiting 15 participants with responsibilities for workplace health, wellbeing and safety, who participated in a semistructured interview about self-management and support. Data were analysed using a qualitative six-stage thematic analysis technique.
\end{abstract}

Purpose: Long-term health conditions are a significant occupational and global burden and can undermine people's ability to work. Workplace support for self-management of long-term conditions has the potential to minimise adverse work effects, by enhancing health and work outcomes. No data exists about employers' views concerning supporting workers with long-term conditions to self-manage.

Findings: Self-management support is not purposely provided to workers with longterm conditions. Support in any form rests on workers disclosing a condition, and on their relationship with their line-manager. While employers have considerable control over people's ability to self-manage, they consider that workers are responsible for selfmanagement at work. Stigma, work demands, and line-manager behaviours are potential obstacles to workers' self-management and support.

Practical implications: Workplace discussions about self-managing long-term conditions at work should be encouraged and opened up, to improve health and work outcomes and aligned with return-to-work and rehabilitation approaches. A wider 
biopsychosocial culture could help ensure workplaces are regarded as settings in which long-term conditions can be self-managed.

Originality: This study highlights that employer self-management support is not provided to workers with long-term conditions in a purposeful way. Workplace support depends on an employer knowing what needs to be supported which, in turn, depends on aspects of disclosure, stigma, work demands and line management. 


\section{Introduction}

Long-term health conditions (LTCs) are a significant occupational and global burden (Hajat and Stein, 2018) affecting people of working age. Long-term health conditions can undermine people's ability to work and reduce their attendance and productivity (Vick and Lightman, 2010). This impact in the workplace is a significant challenge for employers.

The symptoms and effects of many LTCs can be self-managed, especially if selfmanagement support is available, including through primary healthcare services (Anonymous, 2020). Self-management is concerned with the activites people undertake to care for an LTC including managing symptoms, medication or seeking support. In the UK, supported self-management is integral to the NHS's Long-term Plan (NHS, 2020) and concerned with supporting people to actively care for an LTC. Although receiving support might alleviate an LTCs negative work effects (Hjärtström et al., 2018) this does not always happen, and engaging healthcare services with self-management can be difficult (Greenhalgh, 2009; Anonymous, 2020).

In England, the number of people with LTCs in employment has increased in recent years (NHS Digital, 2021), with recent statistics suggesting an employment rate of $65 \%$ for those with LTCs aged between 16-64 years, which amounts to an $11 \%$ employment gap compared with the general employed population (NHS Digital, 2021). Currently, the onus for supporting workers with LTCs largely falls to employers rather than healthcare 
services, which raises questions over the adequacy of current policy and practice for supporting people with LTCs to remain in employment.

The UK's National Institute for Health and Care Excellence (NICE) provides guidance focused on helping employers support peoples' health at work and improving how they manage sickness absence for all their employees, regardless of whether they have a disability or LTC. Indeed, reducing sickness absence and costs is a specific UK policy priority (National Institute for Health and Care Excellence, 2019). Yet NICE guidance is not mandatory to follow nor reguarly commumunicated to employers and, specifically, fails to mention self-management. However, several laws regulate employers' LTC support which mandate workplace policies for managing sickness absence, return-towork and rehabilitation, including through gradual, phased return-to-work programmes and work adjustments (Employment Rights Act, 1996; Health and Safety At Work Act, 1974; Equality Act, 2010). Yet, LTCs and disabilities do not always necessitate sickness absence, return-to-work plans or rehabilitation, suggesting that support needs are not limited to these scenarios. In reality, support is often needed to help workers selfmanage LTCs and disabilities during work and around their job demands.

The Equality Act (2010) is the main law regulating employers' LTC support: it prohibits discrimination and requires employers to make reasonable adjustments (or modifications) to support workers with disabilities. Many people with LTCs, including cancer and multiple sclerosis, are legally classified as disabled (defined as having a physical or mental impairment that has a substantial and long-term adverse effect on 
people's ability to carry out normal day-to-day activities (Equality Act, 2010)). Work adjustments (or modifications) aim to ensure people are not disadvantaged in doing their jobs, and can include changes to accommodate self-management activities (e.g., medication breaks). Nonetheless, since 2017 an average 1,673 disability discrimination cases (including failure to make adjustments) reach tribunal each quarter (Disability Rights UK, 2020). These data provide further evidence for the need to improve workplace LTC support and highlights a potential gap for employer support, akin to workplace support for rehabilitation (Waddell et al., 2008).

Individual, organisational and societal features affect people's LTC self-management (Anonymous, 2020) and it is recommended that workplace support for LTCs could improve (Gignac et al., 2020). However, little research explores self-management support in a workplace setting (Shaw et al., 2014) and none (to our knowledge) from employer perspectives.

Accounting for employers' views is important because providing LTC support could be at the mercy of organisational needs to maintain productivity and minimise cost. While employers are, in principle, in a position to support workers with LTCs and understand their support needs (Stevenson and Farmer, 2017), this has to be set alongside organisational priorities. Thus, employers' views about supporting LTC selfmanagement are an important missing link in devising effective and acceptable workplace self-management support for LTCs, which has not been scoped. 
This study aimed to explore employers' views about workers' LTC self-management and support needs, which are considered essential to guiding workplace intervention design, to provide effective and feasible workplace support (Boger et al., 2015).

Specifically, the study aimed to establish:

(1) what employers understand about workers' LTCs, self-management behaviour(s), and needs for workplace support;

(2) the obstacles to supporting workers' self-management;

(3) how employers' view their role and responsibilities in supporting workers' selfmanagement at work.

\title{
Methods
}

A qualitative approach was taken which is a useful way to explore how groups of people understand and frame a given topic (Heinrichs et al., 2018). Ethical approval was granted by Loughborough University Ethical Committee for Research with human participants in 2016.

\author{
Participants \\ Between March and September 2018, 15 individual participants were recruited, who \\ took part in semi-structured interviews: they represented professionals in health, safety, \\ wellbeing, $\mathrm{HR}$ and occupational health $(\mathrm{OH})$ roles. Participant demographics are \\ presented in Table 1.
}


A purposive sampling method was used to recruit different employer representatives. This approach is suitable given the limited number of accessible participants and a time and cost-effective method. First, employers were recruited from a sample who had distributed an online survey to workers as part of a broader project (anonymous). Eight employers had expressed an interest in being interviewed as part of the survey study. Three were targeted from the private sector (e.g., financial services), four from the public sector (e.g., council) and one from the third sector (e.g., charity). This resulted in six employers agreeing to participate while two (private sector) declined due to work demands. Second, to ensure the representation of unrepresented sectors (e.g., utilities) unknown employer representatives with health, safety and wellbeing responsibilities were identified from their job title. Different sized organisations were approached to ensure the data represented different employers including SME's. Various business sources were used to identify and approach potential participants including via HR networks, publications or Linkedln, and contacted via unsolicited email, or approached in networking meetings. Nine participants were recruited in this way. All participants received a detailed study information sheet, were invited to ask questions and required to provide written consent before interview.

\author{
Interviews \\ Interviews, based on a semi-structured interview schedule informed by the scientific \\ literature, were opened by the reading of a self-management definition: Self- \\ management is a term used to include the actions taken by a person with a long-term
}


health condition to recognise, treat and manage their own health. The schedule included 14 (mandatory) questions divided into three pre-defined sections. Section one explored employers' LTC and self-management awareness, including views about their role and responsibilities (four questions). Section two explored self-management support provided to workers and their perceived support needs (six questions). Section three explored work factors and employers' views about how work affects workers selfmanagement including obstacles and challenges to support (four questions). The lead investigator $(\mathrm{SH})$, trained in interview techniques, conducted the interviews, which lasted between 34 and 62 minutes (averaging 47). Interviews were digitally recorded with participants knowledge and written consent and transcribed verbatim by a professional academic service. Due to geographical considerations, face-to-face interviews were not always possible: nine interviews were conducted by telephone with the remaining six at workplaces. By the twelfth interview, the lead investigator noticed a pattern emerging with participants giving similar responses to questions being asked. After checking the responses across the 12 recordings, the lead author discussed with one co-author for confirmation that the data were sufficient to answer the research questions (Glaser and Strauss, 2017). It was felt data saturation had been reached with an adequate understanding of emergent themes. Therefore, interviewing ended after fifteen employers had participated.

\begin{abstract}
Analysis
Interview transcripts were analysed thematically (by the lead investigator) using Braun and Clarke's (2006) six-stage approach: (1) Following cross-checking for accuracy,
\end{abstract}


transcripts were read and notes made about initial observations, codes and thoughts;

(2) To generate codes, transcripts were re-read and codes developed to include descriptions, meanings and theme ideas; (3) Codes which fitted together were used to form initial themes, resulting in five broad themes and 26 sub-themes, which were discussed and agreed with a co-author (an experienced researcher acting as a 'critical friend' (Smith and Sparkes, 2006); (4) Themes were then reviewed deductively against those from a previous qualitative self-management support study (Dwarswaard et al., 2016) resulting in four final themes in which the sub-themes were consolidated: i) instrumental; ii) psychosocial; iii) relational; and iv) dynamics in self-management support; (5) To enhance credibility, themes were independently checked with the same critical friend before being agreed. Sub-themes under 'dynamics in self-management support' relate to individual, LTC and organisational factors; those under 'instrumental support' relate to workplace support for self-management; those under 'psychosocial support' relate to psychological and emotional resources; and those under 'relational support' relate to beneficial interactions with others. A thematic map is presented in Figure 1. Finally, representative data extracts were identified by re-reading the transcripts alongside the final themes and sub-themes whilst highlighting text sections.

\author{
Results \\ Employer interviewees are referred to as participants and by number in exemplar \\ extracts. Adjustments are referred to as modifications.
}

Theme 1: Dynamics in Self-Management Support. 
Theme one presents participants' knowledge and understanding of LTCs, selfmanagement and support. This establishes the organisational background to the views expressed.

Knowledge and Understanding of LTCs.

Participants were asked about the prevalence of LTCs amongst workers. None was able to provide a precise figure. An $\mathrm{OH}$ specialist described they 'go by who [and the LTCs] they see,' (Participant 5). Some $(n=3)$ speculated about the proportion of workers with LTCs, ranging from five percent for a council to 20 per cent for an NHS hospital. This suggests employers are unaware of the numbers of workers with LTCs. Participants were better able to identify those LTCs they were concerned about managing:

We're most concerned about mental health ...because historically this has been a hard one for the firm to manage or support. Participant 1.

For organisations with manual jobs (i.e., NHS Hospital) musculoskeletal conditions were mentioned as problematic due to their effects on workers' ability to undertake physical job tasks. Participants identified mental health LTCs (including stress, anxiety and depression) as most concerning and predominant reasons for sickness absence.

Knowledge and Understanding of Self-Management. 
For all participants, the terms self-management and self-management support were not a part of routine health and wellbeing terminology. Two participants explained $\mathrm{OH}$ reports not using such terminology. When asked about their understanding of selfmanagement, most $(n=13)$ were unfamiliar with the concepts:

Never heard of it. Self-management? I guess now you mention it, it does make sense, but it doesn't roll off the tongue does it? It sounds like there is a problem. Participant 11.

Despite unfamiliarity with the term, on questioning, participants interpreted selfmanagement support as any action or support provided that could be beneficial (intended or otherwise) to a worker with an LTC, including wellbeing programme features. One participant did not perceive self-management to 'be part of everyday life for people [with LTCs]' (Participant 12). Strikingly, no-one was aware of the scientific evidence for self-management and support.

Participants were asked to provide examples of how workers self-manage at work. One shared:

Regular rest breaks ... a lot of them [self-management activities] are not visible to us. Participant 1. 
Common and visible activities were described. All described self-management behaviour not involving workplace support (e.g., taking a sick day). One helped explain his modest awareness:

If the individual doesn't need modifications from the firm to self-manage their condition, why would they tell us about it? Participant 1.

Knowledge and Understanding of Self-Management Support and the Employer's Role and Responsibilities.

Participants described self-management support as provided in two main ways: 1) via health and wellbeing programmes giving access to information and resources (e.g., an Employee Assistance Programme (EAP)); and 2) via policy interventions managed by managers to help workers maintain working (e.g., modifications). Support described by participants was not specific to workers with LTCs, and for most $(n=11)$ responsibility for specific LTC support was devolved to third parties (i.e., OH), to advise on selfmanagement activities or work modifications.

When asked to summarise their LTC self-management support role and responsibilities, all participants considered this a joint responsibility between employer and worker. Yet, ultimate self-management responsibility was attributed to the worker. One participant shared frustrations with workers who do not take responsibility for an LTC: 
It's almost like people turn up and say, "I've got this condition, now what are you going to do for me?" Participant 4.

Worker vs Employer needs.

Participants were asked about difficulties in providing self-management support. The entire sample envisaged times when work obstructed self-management and support provision. Supporting and prioritising an LTC could be problematic due to work demands. For one participant, the organisation's productivity focus meant empathetic support for people with LTCs is sometimes unavailable:

There is an obvious lack of empathy when work demands are clear. Participant 11.

In the NHS, work demands could encourage presenteeism:

I think when an illness gets in the way, and staff are beholden to what comes through the door... they feel guilty [about taking sick leave]. Participant 7.

Despite these complexities all participants acknowledged the need to reconcile workers' LTC self-management support needs with work demands tensions.

Theme 2: Instrumental Support.

Theme two is concerned with the support participants provide to encourage and enable workers' LTC self-management (or is intended to). 


\section{Workplace Policies and Process.}

When asked about how LTC self-management support is provided, workplace policies and process were described. While not strictly a form of self-management support or concerned with LTCs, most mentioned policies providing a framework in which workers' health can be managed. Policies included flexible working, sickness absence and work modifications. Most policies aimed to support general health, illness and recovery rather than ongoing LTC management, though could potentially support workers' selfmanagement. One participant shared exemplar self-management strategies facilitated by workplace policies:

We're a very understanding organisation, and people can take time off, they can go for medical appointments, all of those sorts of things, and our policies support them to. Participant 4.

It was suggested that policies enable workers with LTCs to take care of themselves and self-manage. Yet, it was recognised the importance of self-management (including the usefulness of policies to self-managing) was not made explicit:

We've got all these policies and procedures in place, but we've never actually gone out and said, you're very important in the self-management of your condition [so use them]. Participant 7. 
Workers might be unaware of the benefits of work policies to their LTC selfmanagement, but neither understand nor make use of them.

\begin{abstract}
All but one participant associated self-management support with two policies: 1) sickness absence; and 2) flexible working. Workers with LTCs might at some point need to self-manage by taking sick leave. The absence support provided by organisations varied. Whilst some provide continuing pay and benefits during absence others (including small and medium enterprises (SME's), operate more informal methods. Inflexible absence policies could make taking sick leave difficult and be at odds with self-managing LTC symptoms. Two large organisations described a Bradford Factor formulaic scheme to manage short-term absence, whereby a weighting (and score) is applied to a worker's absence level (taking account of the number of occurrences and days) in a 52-week rolling period. A warning system operates alongside recommending employer action (e.g., formal warnings). Absences for workers' LTC self-management were not mentioned as being excluded from such schemes.
\end{abstract}

\begin{abstract}
Workers ability to work flexibly varied across organisations. Multiple factors were barriers. In some industries, working patterns (e.g., shift work) inhibited flexibility. Nonetheless, all participants shared a belief flexible working is an important method of support to facilitate self-management:
\end{abstract}

... flexible working is a massive self-help technique for anybody who suffers a psychological or physical long-term illness. Participant 3. 
Except for two organisations, flexible working was not easily accessible, and required formal request via a modifications process. Alternatively, for one participant, a global policy of informal flexible working meant all workers (regardless of LTC status) can, in principle, work flexibly. Consequently, flexibility did not always need to be requested. Their representative explained the policy's enabling effect:

The way in which we encourage flexible working allows to a degree people with LTCs being able to just get on with things without having to come and ask permission. Participant 1.

Similarly, for one SME flexibility was unproblematic:

We're quite flexible ... we don't try and place too many restrictions. Participant 15.

Work Modifications.

Participants linked flexibility with work modifications (otherwise termed adjustments). Modifications aim to reduce the disadvantage workers with LTCs might experience. They are a regulatory consideration for when workers with LTCs qualify as disabled under the UK's Equality Act (2010). All participants highlighted modifications (granting flexibility) for enabling self-management: 
Most people who are self-managing a chronic illness will actually respond amazingly well to an organisation that actually considers making adjustments in the right way. Participant 3.

\begin{abstract}
Modifications were not always possible. For one participant of a large organisation modifications were rare: multiple factors created difficulties including feasibility, leaders' attitudes, cost and work demands. Most participants preferred fixed boundaries to modifications (i.e., written agreements) which could be an additional barrier, inhibiting flexibility to adjust to an LTC including self-managing unexpected symptoms.
\end{abstract}

\title{
Wellbeing Programmes.
}

When explaining available self-management support, participants described health promotion, wellbeing programmes, benefits, and services (e.g., an EAP). Participants consider providing access to resources is supporting workers self-management. Participants spoke of how benefits access can help workers manage and respond to LTC symptoms (e.g., by accessing private health services), address lifestyle risk factors and take preventative care (e.g., having a health assessment). One participant was confused by a lack of benefit usage:

I feel like we have lots of enablers [benefits] for people to self-manage an LTC, and I'm not sure they actually avail themselves of those. Participant 4. 
Specific LTC support were infrequently described and where mentioned, included mental health first aid training $(n=4)$ and on-site physio services $(n=2)$. Programme elements specific to people's knowledge, skills and confidence to self-manage LTCs were not mentioned. Employers anticipate that by providing access to health and wellbeing benefits, workers with LTCs will self-manage. However, most benefits were concerned with care and support for prevention and recovery, yet for many LTCs, these concepts are unfeasible and inappropriate. Some benefits might not actually support self-management (e.g., if private health insurances exclude cover for pre-existing LTCs).

Theme 3: Psychosocial Support.

Theme three presents the workplace support available to workers with LTCs that participants considered helps support and enhance workers' psychological and emotional resources.

\section{Emotional Support.}

All participants mentioned the importance of emotional support to workers with LTCs. An HR practitioner shared:

I think there is a balance to be struck really, between providing sufficient emotional support to people [with LTCs] to feel they can bring their full selves to work... and not be frightened to talk about their condition... and knowing when it's work time... Participant 
First, all participants highlighted the importance of manager support in facilitating selfmanagement. Opinions about how emotional support is demonstrated varied. It was mostly agreed that care, compassion, empathy, and openness mattered. Participants agreed support is demonstrated in the regular day-to-day interactions between managers and workers. One told of how managers providing emotional care and support by listening helped workers self-manage emotions:

You may not be able to do anything about the stress someone [with an LTC] is experiencing, and you can be upfront and say, "there's nothing I can do", but listening to someone is an enormous help to them. Participant 9.

Some participants described workers' experiences of LTC self-management support 'will vary from manager to manager', (Participant 13). A few alluded to difficulties with managers lacking emotion, thus affecting a worker's LTC disclosure, and their permission for modifications. In these situations, participants suggested workers might turn to colleagues.

Indeed, colleague support was considered important by most participants $(n=12)$. This was not always an alternative to manager support, but a complementary and different form (i.e., perceived to be more informal). One participant spoke of the perceived protective effect of colleague support on workers' mental health during a time of peak demand: 
It was almost like they had their own bubble around pressure, and they were looking after each other. Participant 7.

The third type of emotional support described was from $\mathrm{OH}$. Participants whose workplace had access to these services ( $n=10$ or more), explained their expectation was $\mathrm{OH}$ will advise and influence workers self-management via supportive conversations, during which appropriate behaviours would be advised and encouraged. This support was mainly provided through referral services whereby workers with LTCs were referred for review, resulting in a report being sent to a manager or HR. Despite not being specific about occupational health's influence on worker's emotional resources (perhaps because participants have not attended a one-to-one meeting of this kind), one participant shared an example of a referrals vicarious influence on a worker's emotional health via work modifications:

There was a great conversation that came as a result of that with the manager and the occ health team, that actually allowed the manager to make modifications in terms of flexible working hours and mood control for that individual whilst at work. Participant 3.

\section{Psychological Empowerment and Creating an Open and Inclusive Environment.}

All participants wanted workers with LTCs to self-manage at work when needed. A view was shared that workers need to feel confident and empowered to do so. Participants considered an open and inclusive working environment as central to this. To empower 
workers self-management all participants, regardless of organisational size or sector, talked about action taken to enhance inclusivity (e.g., supporting World Mental Health Day). Direct efforts to empower workers, (e.g., a manager encouraging a worker to use counselling services) were described. One participant explained his hope they were:

... empowering employees (with LTCs) to identify things and give them guidance and advice about how to manage their health better. Participant 3.

Inclusive working environments were important to all participants, being characterised by openness, including disclosure and informality. Participants considered inclusive environments to be empowering by enabling choice, thus giving control (autonomy) and permission for workers to be themselves and self-manage. A few shared concerns about supporting workers, given variations in LTCs and support needs. Some experienced workers with LTCs who were more motivated to self-manage than others. One participant talked of the impossibility of knowing what self-management support each worker needs. Worries about providing support when it is hard to spot an issue was shared:

We're not necessarily trained to spot the sign of whether someone's self-managing an LTC or something other than day to day pressures of life. Participant 9.

When participants talked of empowering workers to self-manage, it became clear their thoughts were combined with those about inclusion, disclosure and stigma. Workers 
were not expected to be empowered to self-manage and feel supported if they were unable to be open about an LTC. Two cultural work features were highlighted and considered integral to workers' self-management: openness and permission. These were intertwined in employer's dialogue about stigma and disclosure. Participants believe such factors can have a positive or negative influence on their organisation's support for workers with LTCs.

Openness was spoken about as a state when no or little stigma exists, and a worker feels able to disclose an LTC (e.g., a manager being told in a conversation). For one participant, being able to disclose and talk about an LTC with a manager was fundamental to being empowered to self-manage:

Biggest and foremost is they're able to come forward and tell their manager. Participant 3.

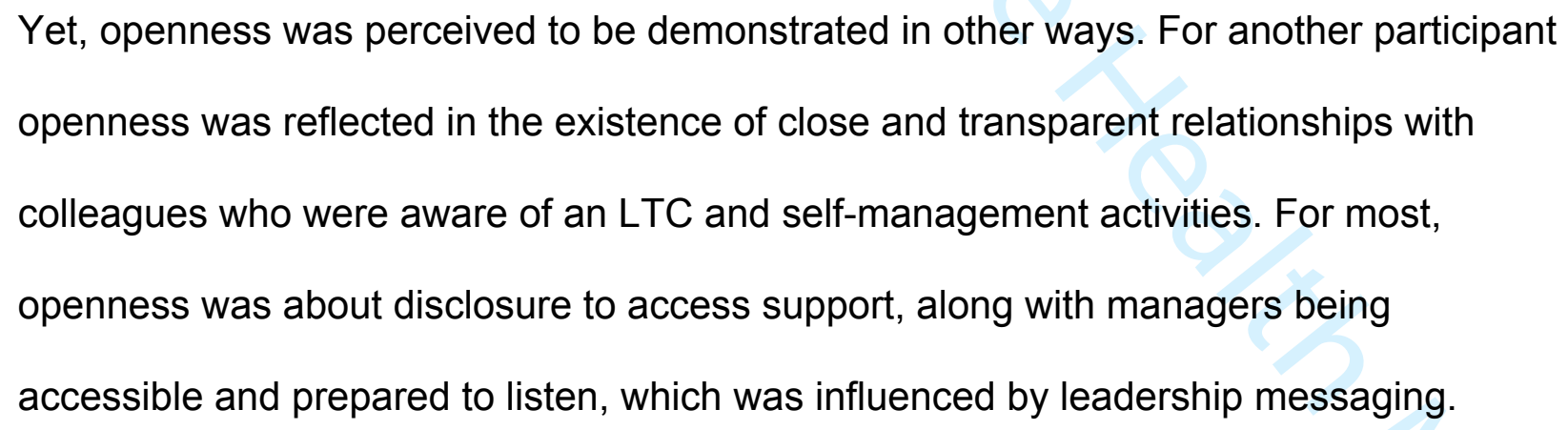
openness was reflected in the existence of close and transparent relationships with colleagues who were aware of an LTC and self-management activities. For most, openness was about disclosure to access support, along with managers being accessible and prepared to listen, which was influenced by leadership messaging. 
Reflecting on what participants had to say, it emerged that relations between openness, permission, stigma and disclosure was viewed as cyclical (see Figure 2). Openness was perceived to help workers feel permitted to disclose an LTC to access support:

We push quite hard with managers, to look at things [support] in the round. Some of that is enabling employees to feel safe to openly disclose their [LTCs] needs. Participant 2.

Workers' disclosure could help break-down stigma and enhance understanding about LTCs, leading to their greater empowerment to self-manage and support because of openness:

I think now people are becoming more aware and understanding of mental health problems, people are getting signposted to better support in the workplace. Participant

9.

Conversely, a lack of openness could affect people's sense of permission to disclose and undermine self-managing.

I think the stumbling block [to self-management] is always for people to actually be open about it [an LTC]. Participant 4. 
This could reinforce stigma, misunderstanding and encourage workers to conceal invisible, stigmatised, and misunderstood LTCs. One participant spoke of the negative and fear-inducing effects of stigma influenced by poor understanding:

I think people are quite fearful, so it [stigma] doesn't encourage people to self-manage [an LTC]... people think it's a scary health condition. Participant 5.

One participant attributed stigma to managers and how 'a certain manager with a certain mindset' (Participant 15) could obstruct disclosure. Most participants had experienced dealing with the negative effects of stigma on people with LTCs. Two participants suggested other reasons for nondisclosure, with some workers being reluctant to speak of an LTC, considering it a non-work matter. An SME participant described a worker who viewed their LTC as a private part of life, thus did not speak of it. The inference was that they self-managed the psychological consequences of their LTC by seeing work as a haven, where they did not have to think or speak of it.

Participants mainly suggested workers with LTCs want emotional support, to feel confident and accepted. In thinking about this and in response to an increase in mental health LTCs, two participants spoke of their efforts to boost psychological and emotional support resources, by enhancing openness and encouraging disclosure. One described:

What we've seen as a result of our mental health awareness drive...is people coming forward. Participant 3. 


\section{Theme 4: Relational Support.}

Participants considered relationships to be important self-management support resources for workers with LTCs. Theme four is concerned with dynamics and traits of relationships, including helpful and beneficial interactions that workers have with relational support sources (i.e., managers).

\section{Sympathy and Empathy.}

Whether people with LTCs have access to helpful relationships at work influences their health behaviours (Anonymous, 2005). Two helpful relationship features stood out: sympathy and empathy. Levels of these traits were suggested to affect workers with LTCs in different ways including their disclosure decisions; their coping with work; and their demands, mood, attendance, performance, confidence, empowerment and selfmanagement decisions. Workers treated with sympathy and empathy were expected to feel cared for and understood, leading to their empowerment to self-manage.

Participants shared how these traits are demonstrated in varying ways including: behaviourally, such as in a manager's tone of voice; in job demands including expected turnaround times; and in operational aspects such as a workers' ability to work flexibly. Two shared their views of these traits:

An understanding when a person says, "I'm in pain and l'm really struggling to walk" instead of almost laughing at it, they need to be, not completely $100 \%$ sympathetic like 
"oh there there", I don't mean that but, I do mean okay, what can we do to support you. Participant 5.

Understanding that person, understanding what they have to go through, probably understanding their LTC a little bit. Participant 9.

\begin{abstract}
An absence of these traits was identified by most as an unhelpful barrier to LTC disclosure, tackling stigma, and work modifications. One participant illustrated the impact in accessing modifications:
\end{abstract}

I think it's [modifications] done under sufferance rather than starting from the point that everyone's got unique requirements and let's work round that. Participant 2.

\begin{abstract}
Boosting sympathy and empathy was suggested to be important because a caring and compassionate approach is better received by workers with LTCs. The business case for this approach to workers and their workability was neatly described:
\end{abstract}

If you show people you care, then they're more likely to come back to work knowing that they'll get support and not waiting until they're absolutely 100 per cent better before they try out the workplace again. Participant 9.

Trust and Confidence. 
Workers' trust and confidence in an organisation (and vice versa) was considered critical to LTC self-management. Participants gave examples of how these factors influence disclosure, performance, conflict, health behaviours, work modifications and help-seeking. One described their aim:

To culturally be mature within the organisation, to be able to trust managers to do the right thing and encourage them [employees]. Participant 3.

Trust and confidence were indicated by managers. Workers whose managers trust them seemed likely to be taken seriously and have LTC-related work modifications sanctioned. This was perceived to have the effect of granting permission, thus having an empowering effect on workers LTC self-management by giving them control.

\section{Line Manager Relationships.}

Managers were considered the key source of relational support for workers and the main influencing factor on people's workplace experiences. Participants considered worker-manager interactions as beneficial under certain conditions, including where a worker is interacting with someone acting in their interests. One public sector participant provided a profile of such a manager:

Someone you can turn to, it's someone you can be honest with and break down some of the fear of talking to line managers. Participant 4. 
Managers were described as interacting with workers with LTCs in two main settings: 1) formally (e.g., during work modification processes); and 2) informally (e.g., during dayto-day interactions). Participants said managers provided self-management support in two main ways: 1) by signposting workers to health and wellbeing resources; and 2) by empowering workers with LTCs to do things themselves. Helpful interactions were frequently described as characterised by a manager having an understanding of a person's need(s), awareness, and understanding of an LTC. Features discussed earlier characterised interactions including honesty, flexibility, empathy, sympathy and care, leading to choice, permission and empowerment. Ultimately, managers are able to give workers the control to self-manage an LTC at work, or not. One participant (with an LTC), gave an example of a manager's trusting approach giving her self-management confidence:

When I had a problem with my sciatic nerve, she was very amenable to, give me a call if you need to work at home...if you don't feel well enough, obviously just let me know. Basically whatever you need to do, I will support you in doing it. Participant 9.

Helpfulness of manager support was considered to be influenced by perceived consistency and fairness of an approach. Most participants speculated about how workers perceptions of fairness connect managers showing care, with permission for flexibility and modifications, positive levels of trust, and confidence. Consistent manager support was recognised as important by all, but it was admitted this was not always achieved and could be a 'lottery': 
It differs from department to department; it depends how good the manager is as to how well-supported the staff [with LTCs] are and that varies greatly. Participant 10.

\begin{abstract}
Participants did not specify reasons for inconsistencies although it was proposed managers' personality, experience and confidence levels, type of work and work demands, all influence the support provided.
\end{abstract}

\begin{abstract}
A healthcare participant alluded to an impact of inconsistencies in broader team support on workers' recovery from LTC episodes:
\end{abstract}

\begin{abstract}
Depending on where you work in the hospital and who your line manager is, or who your team is ... has a plus or minus impact on how you're going to recover. Participant
\end{abstract} 7.

\title{
Discussion
}

The impact of LTCs on people's lives can be helped through self-management. Similarly, workplace support for self-management has the potential to reduce the burden of LTCs on the workplace (Heinrichs et al., 2018). However, little is known about employers' views about supporting workers' LTC self-management. A better understanding of employers' attitudes, beliefs, and practices around self-management support for workers with LTCs will help inform workplace interventions to facilitate better work ability among this population. This study provides new insights into the ways in 
which employers can either support or undermine self-management, and the findings point to ways in which workplaces can help workers to self-manage their LTCs in the work setting.

This study makes three important contributions to our understanding of workplace dynamics and their relationship with self-management support for workers with LTCs. First, self-management support is not purposely provided to workers with LTCs, neither is it a priority for employers. Second, employer support in any form relies on workers' LTC disclosure, which is the crucial step to accessing support. Poor relational support from managers, along with stigma, can undermine open disclosure leading to workers' self-management being (or sensed to be) unpermitted. Third, ultimately employers consider workers themselves are responsible for self-managing at work. Overall, it seems employers might not appreciate the control they exert on workers ability to selfmanage LTCs in the workplace. It is convenient to discuss the detail of the notable findings in relation to the research questions.

\section{Self-Management Concepts and Employer LTC Awareness.}

The single most striking study finding is that employers were uninformed about LTC self-management and any need for support, thus is not purposely provided. Employer support is seen as relating to providing help with workers general health activities including exercise, and generic work policies (including flexible working). Previous research highlights the complexity and diversity of self-management concepts and interpretation problems (Sadler et al., 2014). These findings add to that by 
demonstrating employers do not interpret (or provide) self-management support in an intentional way. This is perhaps because they have not been made aware of their potential role, or a pre-occupation with return-to-work, sickness absence and rehabilitation. Although healthcare services support the principle of patients looking after LTCs themselves, self-management support is not routinely embedded in healthcare settings (Anonymous, 2020; Kennedy et al., 2013). The present findings show selfmanagement support is not embedded in workplace settings either: this signifies a substantial implementation gap, leaving workers struggling with LTCs bereft of support. This position is not helped by the undefined role of employers in healthcare selfmanagement support models, corroborating recommendations for clarity on responsibilities (Williams-Whitt et al., 2016).

However, clarified self-management support models are not necessarily a pre-requisite. The present findings suggest that employers are capable of taking action and learning about workers support needs, should they decide to do so. This lends support to prior recommendations that employers should take a greater role themselves in understanding the needs of workers with LTCs, health problems and disabilities (Kaye et al., 2011; Meng et al., 2017). Despite employers seemingly wanting to support workers with LTCs and lessen adverse effects, a continuing unawareness about selfmanagement support, and what it entails, will make this difficult to achieve.

Workplace Psychosocial Factors Affecting Employer LTC Self-Management Support. 
Employers consider openness a critical form of LTC self-management support. The findings strongly suggest the only way of accessing employer support is through workers disclosing their condition. For employers, openness is reflected in workers decisions to disclose an LTC to a manager, which then signifies a support need. This corroborates a recent study of workplace representatives' views about supporting workers with episodic LTCs (e.g., arthritis or depression) (Gignac et al., 2020), which highlighted non-disclosure as a problem in identifying support needs. It adds to existing evidence by reaffirming disclosure as a critical way of accessing self-management support (Hakkarainen et al., 2017). Furthermore, employers inferred workers' disclosure for self-management purposes could, in itself, help tackle workplace stigma(s). This highlights non-disclosure as an unhelpful cultural barrier for employers, with nondisclosure potentially perpetuating workers own fears and stigma.

Non-disclosure might signify support is not needed, or that a worker is not ready to discuss an LTC. However, the participants in this study recognised that workers might not disclose due to workplace stigma and fear, which has been reported by others (von Schrader et al., 2014). In common with other research (Heinrichs et al., 2018), social acceptance and positive relational support from managers was considered to promote disclosure and enable instrumental support, including through work modifications. This adds to evidence for the importance of workers feeling able to disclose an LTC (Brouwers et al., 2019) to self-manage (Anonymous, 2005), and reflects the pivotal role of managers in ensuring openness (Hakkarainen et al., 2017). Employers apparently appreciate the importance of having an open environment in which disclosure feels 
possible. Yet, while the findings make clear that employers want workers to tell a manager about an LTC, support is not guaranteed. While it cannot be determined if employers' appetite for disclosure is driven exclusively for self-management support reasons, it is clear that disclosure could enable workers with an LTC to self-manage at work, albeit subject to work demands.

\section{Attribution of Self-Management Responsibilities.}

Research suggests attribution of responsibility is important for LTC self-management (Audulv et al., 2010). While people can be in charge of self-managing an LTC they might not actually take charge, seeing other people or factors as responsible. In this study, core self-management responsibilities including disclosure, asking for support, and undertaking self-management activities, were attributed by employers to workers. This is despite activities being largely subject to workplace policies. For example, whilst taking sick leave can be viewed as a form of LTC self-management and absence policies as supportive, these are not without potentially undesirable consequences such as formal warnings issued under a policy. Punitive approaches could undermine and discourage workers self-management responsibilities and promote inappropriate presenteeism.

In contrast and similar to other studies, emotional and instrumental support responsibilities were attributed to managers via disclosure and modifications (Anonymous,, 2005; Anonymous, 2005), reaffirming the influence that managers have on workplace health management (Haafkens et al., 2011). These attributions and view 
of the manager as responsible for more tangible support implies a practical relationship with workers health. This was reinforced by employers' assumptions that workers are active, feel empowered about self-managing an LTC and have controllability. This might not be true of workers' views and abilities. In fact, attributions of personal accountabilities for LTCs could induce stigma and discrimination (Täuber et al., 2018) by giving the impression workers are themselves responsible for health and work outcomes.

The present findings provide new insight into employer perspectives about workplace health and LTC accountabilities. However, as employers do not regularly (if at all) communicate with workers about their LTC self-management and support needs, these could be misattributions. People with LTCs attribute different levels of responsibility, influencing whether they adopt a passive or active role in self-managing an LTC (Audulv et al., 2010). Misunderstandings about responsibilities could mean employers do not provide support when workers need it, leading to confusion about permission to selfmanage at work. Moreover, it is hard to see how workers are responsible (or able) to self-manage at work when their ability to rests largely on whether they can be selfdetermined (i.e., have freedom to modify work). The reality is that the freedom and control workers have is influenced by manager permission and job demands. These attributions and assumed controllability could be at odds and undermine workers LTC self-management. In fact, employers might not realise the control they exert on workers' health. 


\section{Limitations, Implications, Future Research.}

Recruiting employer participants was challenging. While the number of participants representing 'employers' is not high, limiting transferability, the representation from senior health and wellbeing stakeholders from multiple sectors can be considered a strength. Since SME's are underrepresented in workplace health research, inclusion of three in this study is a valuable addition to validity. While small sample sizes are a necessity in interview research, key views can be excluded. Despite this, our findings illuminate an important issue which may be indicative of practices more widely. On reflection, other individuals in the same organisation or different sites could have been approached to achieve a larger more diverse sample. However, this was not feasible within the original constraints of the study. The findings are, of course, based on participant's perceptions, which might be inaccurate, so a methodology including a semi-structured interview framework was used to enable detailed exploration of employers' underlying views. Nevertheless, gaining a broader insight into employers' views to build on these findings will need larger samples, and may benefit from using targeted focus groups. Despite the inclusion of SMEs in this study, given that SME's employ around half of workers (in the UK), they should be represented in future research so that their further contribution to self-management can be included. Research examining employer views about the self-management support needs of workers with less common LTCs (e.g., digestive, neurological, highly stigmatised conditions, and degenerative conditions), and differing workplaces (e.g., home working) would be beneficial, which may involve differing workplace support. 


\section{Summary and Policy Implications}

Employer support for self-management does not appear to be purposely provided to workers with LTCs. While some workers receive support that might empower their selfmanagement, including through work modifications, this is not an employer's main focus. The study highlights that provision of workplace support depends on an employer knowing what needs to be supported, which largely depends on disclosure of an LTC and a workers' relationship with their manager. Manager-worker relations characterised by openness, care and leeway are more likely to support self-management. However, disclosure does not guarantee support, and features of stigma and job demands, along with workers closedness, can undermine support. Workplace discussions about LTC self-management should be opened up to clarify attributions and agree how support activities can be supported and fitted around work. To conclude, employers have considerable control over if and when a worker self-manages an LTC. The findings indicate a need for a wider biopsychosocial culture implemented through policies, processes and training, to ensure the workplace is regarded as a supportive setting in which LTCs and other health problems can and should be self-managed (Kendall et al., 2015).

In conclusion, there are a number of policy implications for self-management support for workers with LTCs. First, it is recommended that healthcare self-management support models are reviewed to account for employers, which could help generate better workplace self-management narratives. Second, a recognition that workable linkages between stakeholders (workers, employers and healthcare) that share information about 
self-management activities (including barriers and facilitators) will help enhance workplace support. Third, existing workplace policies should be reviewed to enable easier access for workers with LTCs to self-modify work: establishing linkages to achieve alignment with return-to-work, rehabilitation, absence and modifications processes would complement this review. Fourth, since LTC awareness is related to help-seeking behaviours (Taylor et al., 2014), government and workplace campaigns focused on LTCs (and managers) need to enhance awareness, tackle stigmatisation and promote disclosure. Fifth, because disclosure is the route to employer support, the issue of LTC disclosure in UK employment must be deliberated: mandatory workplace policies that encourage and facilitate disclosure, with supportive policies and processes kicking in to protect workers (and employers), could nudge disclosure for selfmanagement, thus stimulating employer support. Finally, since it is line managers who can best implement many aspects of self-management support, for LTCs and other work-relevant health problems, evidence-informed information and guidance to enable line managers to play their part is needed, while encouraging buy-in from senior management and business leaders (Ekberg et al., 2016; Kendall et al., 2015). 
Audulv A, Asplund K and Norbergh KG (2010) Who's in charge? The role of responsibility attribution in self-management among people with chronic illness. Patient Education and Counseling. DOI: 10.1016/j.pec.2009.12.007.

Boger E, Ellis J, Latter S, et al. (2015) Self-management and self-management support outcomes: A systematic review and mixed research synthesis of stakeholder views. PLOS ONE. DOI: 10.1371/journal.pone.0130990.

Braun V and Clarke V (2006) Using thematic analysis in psychology. Qualitative Research in Psychology. DOI: 10.1191/1478088706qp063oa.

Brouwers EPM, Joosen MCW, van Zelst C, et al. (2019) To Disclose or Not to Disclose: A Multi-stakeholder Focus Group Study on Mental Health Issues in the Work Environment. Journal of Occupational Rehabilitation. DOI: 10.1007/s10926-01909848-z.

Disability Rights UK (2020) Large Increase in Disability Employment Tribunal Cases. Available at: https://www.disabilityrightsuk.org/news/2020/january/large-increasedisability-employment-discrimination-cases. Accessed 10 May 2021.

Dwarswaard J, Bakker EJM, van Staa A, et al. (2016) Self-management support from the perspective of patients with a chronic condition: A thematic synthesis of qualitative studies. Health Expectations. DOI: 10.1111/hex.12346.

Ekberg K, Pransky G, Besen E, et al. (2016) New Business Structures Creating Organizational Opportunities and Challenges for Work Disability Prevention. Journal of Occupational Rehabilitation 26: 480-489. DOI: 0.1007/s10926-0169671-0.

Employment Rights Act (1996). Available at: https://www.legislation.gov.uk/ 
ukpga/1996/18/part/X Accessed 9 May 2021.

Equality Act (2010). Availalable at: https://www.legislation.gov.uk/ ukpga/2010/15/contents Accessed 9 May 2021.

Gignac MAM, Bowring J, Jetha A, et al. (2020) Disclosure, Privacy and Workplace Accommodation of Episodic Disabilities: Organizational Perspectives on Disability Communication-Support Processes to Sustain Employment. Journal of Occupational Rehabilitation (0123456789). Springer US. DOI: 10.1007/s10926020-09901-2.

Glaser BG and Strauss AL (2017) Discovery of Grounded Theory: Strategies for Qualitative Research. Routledge.

Greenhalgh T (2009) Patient and public involvement in chronic illness: beyond the expert patient. BMJ (Clinical research ed.). DOI: 10.1136/bmj.b49.

Haafkens JA, Kopnina H, Meerman MGM, et al. (2011) Facilitating job retention for chronically ill employees: Perspectives of line managers and human resource managers. BMC Health Services Research. DOI: 10.1186/1472-6963-11-104. Hajat C and Stein E (2018) The global burden of multiple chronic conditions: A narrative review. Preventive Medicine Reports 12(September). Elsevier: 284-293. DOI: 10.1016/j.pmedr.2018.10.008.

Hakkarainen P, Sund R, Arffman M, et al. (2017) Working people with type 1 diabetes in the Finnish population. BMC Public Health 17(1). BioMed Central Ltd. DOI: 10.1186/s12889-017-4723-8.

Anonymous (2020)

Heinrichs K, Angerer P and Loerbroks A (2018) Psychosocial working conditions as 
determinants of asthma self-management at work: A systematic review. Journal of Asthma. DOI: 10.1080/02770903.2017.1396469.

Heinrichs K, Vu-Eickmann P, Hummel S, et al. (2018) What are the perceived influences on asthma self-management at the workplace? A qualitative study. BMJ Open. DOI: 10.1136/bmjopen-2018-022126.

Hjärtström C, Lindahl Norberg A, Johansson G, et al. (2018) To work despite chronic health conditions: A qualitative study of workers at the Swedish Public Employment Service. BMJ Open. DOI: 10.1136/bmjopen-2017-019747.

Kaye HS, Jans LH and Jones EC (2011) Why don't employers hire and retain workers with disabilities? Journal of Occupational Rehabilitation. DOI: 10.1007/s10926-0119302-8.

Kendall NA, Burton K, Lunt J, et al. (2015) Developing an Intervention Toolbox for Common Health Problems in the Workplace. HSE Books.

Kennedy A, Bower P, Reeves D, et al. (2013) Implementation of self management support for long term conditions in routine primary care settings: Cluster randomised controlled trial. BMJ (Online) 9: 129. DOI: 10.1136/bmj.f2882.

Meng L, Wolff MB, Mattick KA, et al. (2017) Strategies for Worksite Health Interventions to Employees with Elevated Risk of Chronic Diseases. Safety and Health at Work 8(2). Elsevier Science B.V.: 117-129. DOI: 10.1016/j.shaw.2016.11.004.

Anonymous (2005)

Anonymous (2005)

National Institute for Health and Care Excellence (2019) Workplace health: long-term sickness absence and capability to work. Available at: https://www.nice.org.uk/ 
guidance/ng146

NHS (2020) Supported self-management. Available at: https://www.england.nhs.uk/wpcontent/uploads/2020/03/supported-self-management-summary-guide.pdf.

NHS Digital (2021) NHS Outcomes Framework Indicators - February 2021 Release.

Available at: https://digital.nhs.uk/data-and-information/publications/statistical/nhsoutcomes-framework/february-2021 (accessed 10 May 2021).

Sadler E, Wolfe CDA and McKevitt C (2014) Lay and health care professional understandings of self-management: A systematic review and narrative synthesis. SAGE Open Medicine. DOI: 10.1177/2050312114544493.

Shaw WS, Besen E, Pransky G, et al. (2014) Manage at work: A randomized, controlled trial of a self-management group intervention to overcome workplace challenges associated with chronic physical health conditions. BMC Public Health 14(1): 1-11. DOI: $10.1186 / 1471-2458-14-515$.

Smith B and Sparkes AC (2006) Narrative inquiry in psychology: Exploring the tensions within. Qualitative Research in Psychology. DOI: 10.1191/1478088706qrp068oa.

Stevenson D and Farmer P (2017) Thriving at Work. The Stevenson/Farmer review of mental health and employers. DOI: 10.1007/978-3-319-69627-0_29-1.

Täuber S, Mulder LB and Flint SW (2018) The impact of workplace health promotion programs emphasizing individual responsibility on weight stigma and discrimination. Frontiers in Psychology 9(NOV): 1-18. DOI: 10.3389/ fpsyg.2018.02206.

Taylor SJ, Pinnock H, Epiphaniou E, et al. (2014) A rapid synthesis of the evidence on interventions supporting self-management for people with long-term conditions: 
PRISMS - Practical systematic Revlew of Self-Management Support for long-term conditions. Health Services and Delivery Research 2(53). National Institute for Health Research: 1-580. DOI: 10.3310/hsdr02530.

Vick A and Lightman E (2010) Barriers to employment among women with complex episodic disabilities. Journal of Disability Policy Studies 21(2): 70-80. DOI: $10.1177 / 1044207309358588$.

von Schrader S, Malzer V and Bruyère S (2014) Perspectives on Disability Disclosure: The Importance of Employer Practices and Workplace Climate. Employee Responsibilities and Rights Journal 26(4): 237-255. DOI: 10.1007/s10672-0139227-9.

Waddell G, Burton K and Kendall N (2008) Vocational Rehabilitation What Works, for Whom , and When? Vocational Rehabilitation Task Group: 1-309. DOI: 10.1017/ S0033291705215866.

Williams-Whitt K, Bültmann U, Benjamin •, et al. (2016) Workplace Interventions to Prevent Disability from Both the Scientific and Practice Perspectives: A Comparison of Scientific Literature, Grey Literature and Stakeholder Observations. J Occup Rehabil 26: 417-433. DOI: 10.1007/s10926-016-9664-z. 
TABLE 1. Participant Demographic Characteristics.

\begin{tabular}{|c|c|c|c|c|c|c|}
\hline Participant & Sector & Size & Gender & Specialism & Manager & Tenure (yrs) \\
\hline 1 & Private sector - professional services & $>500$ & Male & $\mathrm{HR}$ & Yes & 15 \\
\hline 2 & Private sector - food and drink & $>500$ & Male & Occupational health & Yes & 6 \\
\hline 3 & Private sector - utilities & $>500$ & Male & Health and safety & Yes & 4 \\
\hline 4 & Public sector - finance & $>500$ & Female & $\mathrm{HR}$ & Yes & 3 \\
\hline 5 & Public sector - education & $>500$ & Female & Occupational health & Unknown & 3 \\
\hline 6 & Public sector - technology & $>500$ & Male & Technical & Yes & 2 \\
\hline 7 & Public sector - NHS Hospital & $>500$ & Male & $\mathrm{HR}$ & Yes & 2 \\
\hline 8 & Private sector - healthcare & $>500$ & Female & $H R$ & Yes & 1 \\
\hline 9 & Public sector - council & $>500$ & Female & $\mathrm{HR}$ & Unknown & - \\
\hline 10 & Public sector - education & $>500$ & Female & $\mathrm{HR}$ & Unknown & - \\
\hline 11 & Private sector - financial services & $>500$ & Male & $\mathrm{HR}$ & Yes & 2 \\
\hline 12 & Private sector - financial services & $>500$ & Female & $\mathrm{HR}$ & Yes & 1 \\
\hline 13 & Public sector - council & $250-500$ & Female & Facilities & Unknown & - \\
\hline 14 & Private sector - recruitment & $50-249$ & Male & Business owner & Yes & 13 \\
\hline 15 & Third sector - charity & $50-249$ & Female & $H R$ & Yes & 8 \\
\hline
\end{tabular}


FIGURE 1. Thematic Map of the Final Themes and Sub-themes. 
